\title{
Erratum to: Tracking control of a piezoelectric actuator with hysteresis compensation using RST digital controller
}

\author{
Irfan Ahmad $^{1}$ Akram M. Abdurraqeeb ${ }^{1}$
}

Published online: 10 December 2016

(C) Springer-Verlag Berlin Heidelberg 2016

\section{Erratum to: Microsyst Technol \\ DOI 10.1007/s00542-016-3213-8}

Unfortunately, the eighth sentence of the Abstract contains an error in the original publication.

The correct sentence is given below:

The peak to peak tracking error of less than $2 \%$ for the desired displacement of $18 \mu \mathrm{m}$ with tracking frequency of $10 \mathrm{~Hz}$ is also achieved. The original article has been updated accordingly.

The online version of the original article can be found under doi:10.1007/s00542-016-3213-8.

Irfan Ahmad

irfahmad@ksu.edu.sa

Akram M. Abdurraqeeb

encom.akram@gmail.com

1 Electrical Engineering Department, College of Engineering,

King Saud University, Riyadh, Saudi Arabia 